\title{
News and Names of the Danish Society of Diagnostic Ultrasound
}

It is with honor and great pleasure that DUDS announces recent individual achievements and contributions to the science and application of ultrasound in medicine.

\section{Young Investigator First-Place Award \\ $\nabla$}

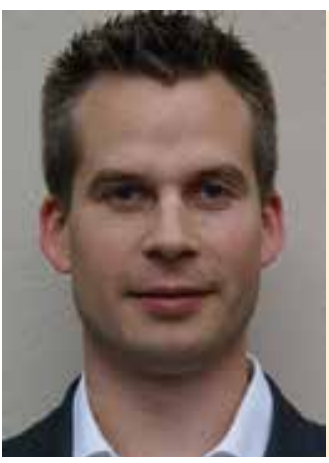

Dr. Rune Wilkens

DUDS congratulates Dr. Rune Wilkens with the New Investigator First-Place Award at the AIUM/WFUMB Convention, Florida, USA, March 2015 for the presentation of clinical ultrasound with the title „Impact of Ultrasound on Classification and Management of Crohn's Disease Patients With Inconclusive Colonoscopy“.

\section{Scientific Award}

$\nabla$

DUDS congratulates Dr. Flemming Forsberg, $\mathrm{PhD}$, who received the Joseph $\mathrm{H}$. Holmes Basic Science Pioneer Award by AIUM (American Institute of Ultrasound in Medicine and Biology). Dr. Forsberg is currently Professor in Radiology and head of research for the Jefferson Ultrasound Institute at Thomas Jefferson University.

\section{Doctoral thesis \\ $\nabla$}

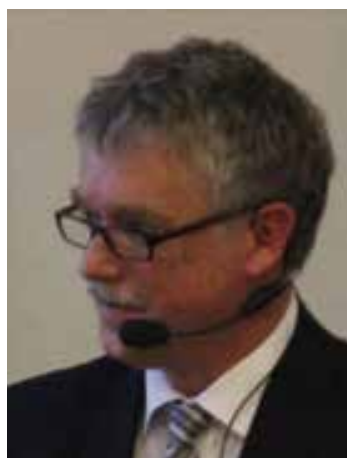

Dr. Søren R Rafaelsen

DUDS congratulates DMSci Søren Rafael Rafaelsen with his successful defence of his doctoral thesis with the title "Diagnostic Ultrasound in Colorecteral Cancer". Søren is assistant professor at the Institute of Regional Health, University of Southern Denmark and consultant radiologist at the Department of Radiology, Vejle Hospital, Denmark.
President Elect, WFUMB

$\nabla$

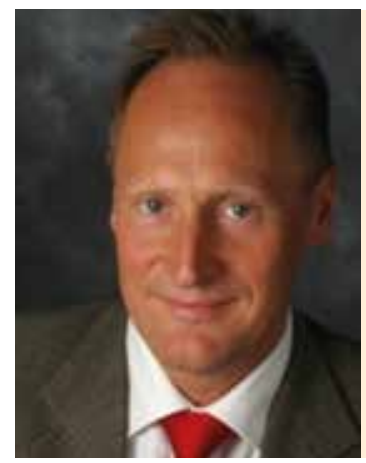

Dr. Christian P. Nolsøe

DUDS congratulates Dr. Christian Pállson Nolsøe, PhD with the position as President Elect of the World Federation for Ultrasound in Medicine and Biology. Christian is assistant professor at the Center of Clinical Education, Rigshospitalet, Copenhagen University, Denmark and consultant radiologist at Department of Gastroenterology and Surgical Gastroenterology at Herlev Hospital, Copenhagen University Hospital, Denmark. 